\title{
Los lazos de los gauchos. La sociabilidad como herramienta para la difusión de la tradición en la provincia de Buenos Aires, 1930-1950
}

\author{
Ties of the "gauchos". \\ Sociability as a tool for dissemination \\ of tradition in Buenos Aires, 1930-1950
}

\author{
Matías Emiliano Casas \\ Consejo Nacional de Investigaciones Científicas y Técnicas \\ Universidad Nacional de Tres de Febrero
}

(Argentina)

matiasemiliano@hotmail.com

El crecimiento y la expansión de los centros tradicionalistas bonaerenses durante la década del cuarenta estuvieron relacionados al entramado social que supieron construir desde sus inicios. Las redes vinculares se fueron expandiendo en la medida que las agrupaciones se consolidaban en la organización y en la participación de los socios. Este artículo se propone explorar las relaciones tejidas desde dos de los centros tradicionalistas de mayor influencia en la provincia de Buenos Aires: el Círculo Tradicional Leales y Pampeanos, de Avellaneda; y el Círculo Criollo El Rodeo, de Santos Lugares. Se considera que a partir de sus conexiones, los tradicionalistas contaban con una serie de variantes para presentar sus actuaciones, desfiles, prácticas ecuestres y celebraciones criollas que contribuyeron a consolidar la figura del gaucho como símbolo para la identidad nacional. Los socios, ataviados a la usanza gauchesca, eran recurrentemente solicitados desde clubes sociales, parroquias, regimientos militares, círculos de obreros, agrupaciones políticas y organismos municipales para fiestas, inauguraciones y homenajes. Se pretende aquí analizar las características de esos vínculos y las condiciones de posibilidad que éstos generaban para la reproducción de la tradición. La correspondencia y las publicaciones de esas agrupaciones ponían de relieve una experiencia eminentemente social que fue regulando una serie de pautas, modos y conductas para las prácticas tradicionalistas.

Palabras Clave: Centros tradicionalistas - Gaucho - Tradición - Provincia de Buenos Aires 


\begin{abstract}
In the forties, the growth and expantion of the traditional centers in Buenos Aires were connected with the social ties they had built. The relational networks expanded as the groups consolidated their organizations and the participation of the their partners. This article endeavors to explain the relationships inside two of the most influential traditionalist centers in the province of Buenos Aires: "Círculo Tradicional Leales y Pampeanos" of Avellaneda" and "Círculo Criollo El Rodeo” of Santos Lugares.

We consider that the traditionalists had a set of variants for preparing their performances, parades, equestrian practices and creole celebrations that contributed to the consolidation of the "gaucho" as a national symbol. The partners, dressed in the gaucho customes, were frequently requested from social clubs, churches, military regiments, worker circles, political groups and municipal agencies for parties, openings and tributes. We analyze the characteristics of these links and the enabling conditions created by them for the reproduction of the tradition. The correspondence and publications of these groups showed mostly a social experience that generated patterns, models and behaviors of the traditionalist practices.
\end{abstract}

Key Words: Traditional centers - Gaucho - Tradition - Buenos Aires

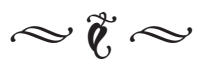

\section{Introducción}

Los círculos criollos surgieron a fines del siglo XIX en diferentes puntos de la campaña y las urbes rioplatenses. Los pequeños grupos que se reunían para recuperar costumbres camperas amenazadas ante los avatares de la modernidad, exaltaban desde las payadas y los fogones la figura del gaucho en tanto condensación de una serie de atributos morales y patrióticos que se pretendían modelo para sus coyunturas. El crecimiento y la expansión de los centros tradicionalistas bonaerenses durante la década del cuarenta estuvieron relacionados con el entramado social que supieron construir desde sus inicios. Al afán gubernamental por oficializar la ligazón entre tradición, campo y gaucho, los tradicionalistas incorporaron una red vincular particular que trascendió, ampliamente, los espacios destinados exclusivamente a esa reivindicación.

El primer registro de un centro tradicionalista se conoció en Montevideo cuando el Doctor Elías Regules fundó la novel asociación criolla, en 1894, que se presentó en sociedad con un desfile a la usanza gauchesca por la avenida 18 de Julio. Cabe detenerse en el gestor de la experiencia en tanto su apellido quedaría fijado como equivalente de la tradición campera en ambos márgenes del Río de la Plata. La familia 
del escritor costumbrista poseía estancias en el departamento de Durazno donde pasó gran parte de su infancia conviviendo con gauchos, lo que habría motivado, de acuerdo a sus argumentaciones, el amor por el ámbito rural. ${ }^{1}$ En el trayecto de sus estudios universitarios, Regules mostró indicios precisos sobre su carácter asociacionista y fomentó la creación de la "Sociedad Universitaria" que otorgaba cursos gratuitos a los estudiantes iniciales para respaldarlos en el comienzo de la carrera.

$\mathrm{Su}$ preocupación por los "malos orientales" a quienes identificaba con un culto excesivo por todo lo allende al Atlántico y que, según su perspectiva, "intoxicaban" la capital uruguaya con sus preferencias, determinaron una continua defensa de las tradiciones camperas y de la figura del gaucho como conservación de lo autóctono. En esa cruzada, Regules no solo empleaba las herramientas de la sociedad criolla y los textos literarios, sino que promovió, además, la escenificación de obras gauchescas de manera conjunta con la compañía teatral y circense Scotti-Podestá. Sus guiones, como sus poesías, trascendieron las fronteras de su agrupación y se cristalizaron como exponentes del tradicionalismo rioplatense. ${ }^{2}$

La inquietud señalada motorizó la dimensión pública de la agrupación criolla. Tal como lo marcó la primera acción orgánica, la práctica de desfilar en la urbe constituía una de las expresiones más recurrentes para los tradicionalistas. La simbología del paseo a

1. REGULES, Elías, Versos Criollos, C. García y Cía., Montevideo, 1935, p. 6.

2. CARÁMBULA DE BARREIRO, Margarita, "Elías Regules (1861-1929)”, en Revista del Sindicato Médico del Uruguay, Montevideo, 1987, p. 7-13. Disponible en: <http://www.smu.org.uy/publicaciones/libros/ejemplares/ regules.pdf $>$ [Consulta:10 de enero de 2016] caballo para mostrarse ante los ciudadanos de a pie conllevaba una significación particular que entremezclaba rasgos de pertenencia, de exclusión, de virilidad y de ruptura. Los tiempos citadinos se resquebrajaban al paso de los "centauros" que entre banderas uruguayas modelaban como reservorios de la tradición. Como plantea Ángel Rama, allí se encontraba la génesis de la "gauchesca domesticada". La agrupación de Elías Regules evidenciaba otro de los caracteres propios de esas asociaciones: el ordenamiento. El gaucho indómito respondía allí a una serie de pautas y normativas establecidas en un marco regulatorio que no solo garantizaría la pervivencia de los centros tradicionalistas, sino que, en algunos casos, se transformaría en su raison d'être.

Ese carácter indómito que se pretendía matizar -o incluso corregir- desde los centros tradicionalistas fue destacado por quienes cuestionaron las reivindicaciones de su figura y su pertinencia como arquetipo de la tradición. En efecto, el propio Regules se encontró atravesado por una serie de polémicas que ocuparon páginas en la prensa uruguaya sobre la funcionalidad de la sociedad criolla y su ligazón con los elementos autóctonos de la cultura rioplatense. ${ }^{3}$ Lo que se ponía en cuestión por quienes eran identificados como los "detractores del gaucho" se podría separar en dos críticas fundamentales: la primera -y más radical- cuestionaba al gaucho como posible modelo de atributos y valores a propagar en las generaciones futuras; la segunda se detenía en el carácter "artificial" de los centros criollos apuntando la puesta en escena que antecedía cada una de sus intervenciones públicas.

3. RAMA, Ángel, Los gauchipolíticos rioplatenses, Centro Editor de América Latina, Buenos Aires, 1994, pp. 152153. 
En el primero de los casos, la máxima referencia atacada por el tradicionalismo argentino fue el historiador Emilio Coni. Sus conferencias y ensayos, recopilados en el libro que se editó post mortem titulado El gaucho, Argentina, Brasil, Uruguay, en 1945, se cristalizaron como la máxima oposición a la identificación del gaucho y la identidad nacional. El autor desestimó su participación en las tropas que combatieron por emanciparse de España y su legado en la construcción del Estado nacional. Para Coni, el modelo de patriotismo que se quería consolidar desde las asociaciones criollas, carecía de los atributos necesarios e identificaba esa operación como un intento más de la región pampeana por imponer su supremacía cultural en el resto del territorio nacional. ${ }^{4}$

Cuando las inquisiciones se dirigían a las experiencias de los centros tradicionalistas, sin realizar escala en el gaucho, se ponía de relieve la legitimidad de sus integrantes para portar la indumentaria gauchesca y presentarse como representantes y reservorios de un tiempo pretérito. El primer desfile en Uruguay, motivó la crítica del periodista Carlos Blixen, quien escribió en el diario La Razón de Uruguay: "Ayer a la tarde llegaron hasta el centro de la ciudad los miembros de esta original Asociación. Venían a caballo... y formaban una columna imponente de doscientos gauchos artificiales. ${ }^{\circ} \mathrm{La}$ referencia con respecto a la falta de autenticidad de los "gauchos" también se reprodujo en relación a las experiencias bonaerenses.

4. CONI, Emilio, El gaucho, Argentina, Brasil, Uruguay, Solar / Hachette, Buenos Aires, 1969, p. 118.

5. GUARNIERI, Carlos, Versos gauchescos y nativistas, DISA, Montevideo, 1970, p. 26.

140
En la década del cuarenta, el escritor y profesor universitario Pedro de Paoli dedicó un estudio particular a la figura del gaucho y su participación en las distintas etapas de la historia nacional. En el libro que publicó como fruto de su pesquisa remarcó críticamente, al igual que Coni, la preponderancia de la provincia de Buenos Aires sobre el interior del país a lo largo de la historia. Entre sus cuestionamientos se involucra a los centros tradicionalistas que recreaban faenas camperas aggiornadas para su exhibición. Según de Paoli, las premisas de esas agrupaciones consistían en representar las formas exteriores del gaucho despreocupándose por el fondo. Es decir, controlaban estrictamente el respeto por el vestuario y los accesorios pero todo consistía en una ornamentación más de lo que constituía un mero espectáculo. De ese modo, las condiciones laborales, la explotación y las persecuciones sufridas por el gaucho, en las que el autor hacía especial hincapié, quedaban soslayadas en las exhibiciones de los centros tradicionalistas. ${ }^{6}$

Más allá de las referencias citadas, las asociaciones de gauchos que proliferaron desde los últimos años del siglo XIX no motivaron una frondosa bibliografía analítica sobre sus experiencias. Breves menciones en estudios de las primeras décadas del siglo XX testimoniaban su pervivencia y el carácter gestacional en orden a la cantidad de los integrantes y las escasas intervenciones públicas. ${ }^{7}$ Ningún trabajo amplio y particular con pretensión científica concentró su atención en la historización de

6. DE PAOLI, Pedro, Trayectoria del gaucho, Ciordia y Rodríguez, Buenos Aires, 1949, pp. 8-9.

7. Ver, por ejemplo, LEHMANN NITSCHE, Robert, Santos Vega, Imprenta de Coni Hermanos, Buenos Aires, 1917 , p. 379. 
esas agrupaciones. Sin embargo, atendiendo los intereses de este artículo, cabe destacar tres estudios que conforman un punto de partida ineludible para su desarrollo.

El clásico libro de Adolfo Prieto, El discurso criollista en la formación de la Argentina moderna, estableció algunas precisiones sobre la funcionalidad de los centros tradicionalistas en la coyuntura del centenario de la Revolución de Mayo. De acuerdo al autor, esas asociaciones favorecían la integración de inmigrantes que encontraban un espacio de asimilación plausible, no solo para mitigar las afrentas xenófobas, sino como una vía de acceso a la identidad nacional que se ponía de relieve en las manifestaciones gauchescas. Prieto, al reparar en el número de los integrantes y en la vitalidad de las experiencias criollistas identificaba su languidecimiento y posterior extinción hacia la década del veinte. ${ }^{8}$ Resulta menester para este trabajo confrontar la interpretación del autor a partir de las agrupaciones surgidas y vinculadas en el período aquí estudiado.

Desde la antropología se realizaron aportes centrales para comprender la vigencia de las asociaciones criollas en la actualidad. En el artículo de Hugo Ratier "Organizaciones rurales y cultura de las pampas" se pondera el asociativismo tradicionalista en la conformación de la cultura rural bonaerense. El estudio se concentra a finales de la década del noventa en las zonas interiores de la provincia. Allí, a diferencia de lo que se mostrará en este trabajo, los integrantes de las agrupaciones transcurren su vida cotidiana en un ambiente similar al que se recrea en las exhibiciones. El contexto campero opera

8. PRIETO, Adolfo, El discurso criollista en la formación de la Argentina moderna, Editorial Sudamericana, Buenos Aires, 1988, p. 184. a favor de la autenticidad de los gauchos que muestran su porte en los desfiles o confirman sus habilidades como jinetes en las domas. ${ }^{9}$

El cuadro de las agrupaciones criollas en la provincia de Buenos Aires se encuentra sistematizado en el libro Presente de gauchos de María Cecilia Pisarello. Ese trabajo se corresponde a un objetivo manifiesto de la autora relacionado con la sistematización de datos sobre los gauchos bonaerenses. Las fichas técnicas que completaban las instituciones incorporadas poco aportan a los propósitos de nuestro trabajo. Empero, determinadas conceptualizaciones de Pisarello introducen un tópico central para pensar a los centros tradicionalistas. En su libro se da por cristalizada la relación entre los "gauchos" y el patriotismo. En algún punto, reproduciendo el discurso esencialista de las agrupaciones, la autora clasifica a los socios como verdaderos patriotas, defensores de un ideario nacional. ${ }^{10}$ Creemos, en cambio, que esa pretendida identificación fue más fruto de una serie de políticas específicas e interacciones sociales que una vinculación esencial de lo gauchesco con la identidad nacional.

A partir de la oficialización del Día de la Tradición en 1939, la ligazón del gaucho con la "argentinidad" fue extendiendo su consenso a un ritmo acelerado. En ese marco, en distintas localidades bonaerenses se multiplicó la presencia de los círculos criollos. Esas agrupaciones presentaron prácticas comunes

9. RATIER, Hugo et al., "Organizaciones rurales y cultura de las pampas: La construcción social de lo gauchesco y sus implicaciones", en Etnia, Buenos Aires, 2002-2004, No 44-45, pp. 81-96.

10. PISARELLO, María Cecilia, Presente de Gauchos, Editorial Unión del Personal Civil de la Nación, Buenos Aires, 2004, pp. 12-16. 
como: actividades hípicas, domas, carreras de sortija, partidos de pato, danzas y recitales folklóricos, payadas a contrapunto, fogones criollos y comidas tradicionales. Los vínculos allí establecidos se caracterizaban por una marcada filiación cultural e identitaria. En términos de Hugo Ratier, las "situaciones gauchescas" que se escenificaban en esos espacios generaban la convergencia de socios provenientes de diversos sectores que, una vez finalizado el encuentro, guardaban sus trajes "gauchos" y retomaban sus tareas cotidianas. ${ }^{11}$ La expansión de esas agrupaciones por la provincia exacerbó las celebraciones al gaucho y a la tradición, desde una narrativa nacionalista y tradicionalista. Este artículo se propone explorar las relaciones tejidas desde dos de los círculos de mayor influencia en el conurbano bonaerense: el Círculo Tradicional Leales y Pampeanos, de Avellaneda; y el Círculo Criollo E1 Rodeo, de Santos Lugares.

Para esbozar las dinámicas propias de las dos asociaciones se consultaron sus archivos privados y las publicaciones que se gestaban a partir del trabajo colaborativo de sus socios. En el Círculo Criollo El Rodeo se conservan los libros de actas y las carpetas con correspondencia diversa desde el momento de su fundación. Además, un conjunto seriado de recortes periodísticos con fotografías complementan un vasto material que habilita la reconstrucción de la agrupación. Para el caso de los tradicionalistas de Avellaneda, la principal fuente de consulta fue su revista La Carreta que condensó diferentes temáticas referidas al devenir de la asociación y a cuestiones más generales del ámbito gauchesco bonaerense.

11. RATIER, Hugo et al., "Organizaciones...”, Op. Cit.

\section{Leales y Pampeanos, la promoción de la tradición en Avellaneda}

La agrupación gaucha de mayor relevancia para la zona sur del Gran Buenos Aires era, en el contexto de la sanción del Día de la Tradición, el Círculo Tradicional Leales y Pampeanos. La historia de esa agrupación evidenció una modalidad particular para la difusión de la tradición que se centralizó en las actividades artísticas, particularmente a partir de la puesta en escena de diversas obras costumbristas, y en el desarrollo de una escuela propia para la enseñanza de danzas tradicionales que trascendió por mucho la simple reproductibilidad de números bailables y apuntó a conformarse como un bastión para la pervivencia de costumbres y conductas del "buen tradicionalista".

La historia de fundación de Leales y Pampeanos resaltaba dos características centrales que apuntaban por un lado a posicionar la zona como poblado histórico y tradicionalista y por el otro a trazar puentes de continuidad con las experiencias primarias de asociaciones gauchescas señaladas más arriba. En los relatos por el XX aniversario de la creación del Círculo, uno de los tradicionalistas de mayor antigüedad de la zona fue el encargado de narrar los antecedentes. Amaro Guira había sido uno de los fundadores del Centro Criollo Los Pampeanos, el 23 de marzo de 1903. Esa agrupación se conformó como un núcleo organizador de veladas criollas con bailes, corridas de sortija y desfiles por las calles de Avellaneda (en ese momento denominado Barracas al Sud) en los primeros años del siglo XX. En un ambiente bien 
diferenciado de la ciudad que se convocaba ante sus anécdotas, Guira describía al pago de entonces con la fisonomía típica de las zonas rurales, con amplios espacios para las faenas ganaderas y con los ombúes para reconfortar a su sombra el descanso de los gauchos.

Los Pampeanos tuvieron una vocación particular por la promoción del teatro gauchesco. Una de las primeras actividades públicas fue la presentación de su conjunto artístico con obras como Tranquera y Justicia Criolla. La cuestión edilicia para el ensayo y preparación determinaron su mudanza y, junto con ella, la división del Círculo. Los tradicionalistas que continuaron con sus reuniones en el viejo local de origen, haciendo alusión a su pervivencia se hicieron llamar Los Leales. La trayectoria de ambas agrupaciones que comenzaron a languidecer en la década del diez marcó una huella insoslayable para los cultivadores de la tradición en Avellaneda. ${ }^{12}$ La decisión de denominar a la agrupación concebida en 1932, Leales y Pampeanos, estaba ligada a las experiencias predecesoras. La herencia pretendida no solo se plasmó en la denominación sino que también se consolidaron los vínculos con las instituciones civiles del municipio que habían establecido contactos y convocado las presentaciones de los pioneros círculos criollos. La actividad teatral, como se verá más adelante, fue uno de los pilares de la agrupación en la década del treinta tal como lo había sido en los comienzos de Los Pampeanos.

Al momento de la fundación de Leales y Pampeanos, la retórica nacionalista se

12. Conferencia de Amaro Guira, transcripta en $\mathrm{La}$ Carreta, órgano del Círculo Tradicional Leales y Pampeanos, Avellaneda, mayo-junio de 1952, pp. 5-12. había expandido hacia diferentes esferas de la sociedad. El integrismo católico, los núcleos nacionalistas en las Fuerzas Armadas, las reivindicaciones patrióticas en los ámbitos educativos, la animadversión al cosmopolitismo, las publicaciones periódicas abocadas a la propagación de esas ideas junto con las diferentes medidas políticas -como por ejemplo la aplicación de la Ley de Residencia contra los extranjeros "perturbadores" del orden establecido- constituían un clima de época favorable para la recuperación y reconfiguración de símbolos ligados a la "argentinidad". ${ }^{13}$

Como plantea Fernando Devoto, a partir de la década del veinte comenzó a manifestarse en el país un nacionalismo antiliberal y autoritario que en alguna medida se disputaba -e interactuaba- con las tradiciones liberales y democráticas. ${ }^{14}$ En pos de rastrear la "primera generación nacionalista", el autor se detiene en las obras de Manuel Gálvez, Leopoldo Lugones y Ricardo Rojas. Los tres intelectuales -con variada intensidad- habían realizado intervenciones en relación al gaucho y la vida

13. Ver MALLIMACI, Arturo, El catolicismo integral en la Argentina, 1930- 1946, Editorial Biblos, Buenos Aires, 1988; ZANATTA, Loris, Del estado liberal a la nación católica: iglesia y ejército en los orígenes del peronismo, 1930-1943, Universidad Nacional de Quilmes, Bernal, 1996; LIDA, Miranda, "Por una historia política y social del catolicismo en la Argentina del siglo XX, en PolHis, Mar del Plata, 2011, No 8, pp. 121-128; POTASH, Robert, El Ejército y la política en la Argentina, 1928-1945, Sudamericana, Buenos Aires, 1981; AMUCHÁSTEGUI, Martha, "Los rituales patrióticos en la escuela pública”, en Adriana PUIGGRÓS, (directora) Discursos pedagógicos e imaginario social en el peronismo (1945-1955), Editorial Galerna, Buenos Aires, 1995, pp. 13-41.

14. DEVOTO, Fernando, Nacionalismo, fascismo y tradicionalismo en la Argentina moderna, Siglo Veintiuno Editores, Buenos Aires, 2005, pp. 26. 
rural anticipando la funcionalidad de esas figuras para las afirmaciones nacionalistas. ${ }^{15}$

En el centro tradicionalista de Avellaneda, la ligazón entre el gaucho y la nacionalidad ocupaba un eje central de sus discursos y actividades. En sus manifestaciones públicas recuperaron varios de los tópicos presentes a comienzos de siglo, entre ellos, la clasificación del municipio como "pueblo gaucho". Durante las celebraciones del centenario del lugar, en 1952, la revista de Leales y Pampeanos advertía la oportunidad de ligarse a los festejos publicando una serie de artículos para confirmar la representación de la "Avellaneda gaucha" ${ }^{16}$ Uno de los argumentos que se presentaba para legitimar ese adjetivo estaba relacionado con la hospitalidad. En Avellaneda, y en sus primeros círculos criollos, habían encontrado refugio migrantes vascos y gallegos que llegaban para trabajar en los frigoríficos de la zona. En congruencia con la funcionalidad presentada por Adolfo Prieto, el presidente del Centro Gallego de Avellaneda, era miembro activo y permanente colaborador de Los Pampeanos. ${ }^{17}$ Si bien la carencia de registros societarios limita la aproximación hacia la trayectoria de los miembros que no participaban en las publicaciones de La Carreta, es factible que esa hospitalidad también haya sido referida en

15. El caso de Lugones fue el más recuperado desde los ámbitos tradicionalistas en orden a sus famosas conferencias en el teatro Odeón en 1913, que luego se editaron en 1916. LUGONES, Leopoldo, El payador, Otero y Co. Impresores, Buenos Aires, 1916.

16. En una editorial de la revista se incluía el poema titulado "Gaucha ciudad centurial" que afirmaba: "Te mire por ande quiera / sos gaucha de corazón”, ver, La Carreta, órgano del Círculo Tradicional Leales y Pampeanos, Avellaneda, marzo-abril de 1952, p. 2.

17. Conferencia de Amaro Guira, transcripta en La Carreta, órgano del Círculo Tradicional Leales y Pampeanos, Avellaneda, mayo-junio de 1952, pp. 5-12. relación a los migrantes internos. La ciudad que se proponía gaucha era uno de los polos industriales más importantes de Buenos Aires de los años treinta, característica que la posicionaba como lugar de atracción para las poblaciones rurales golpeadas por la crisis agrícola.

Esa apertura hacia los inmigrantes se sostuvo en la nueva agrupación fundada en 1932. E1 austríaco Rodolfo Nicanor Kruzich era uno de los oradores recurrentes en los festejos criollos. $\mathrm{Su}$ participación, como representante, en las Fiestas de la Tradición, fomentó relaciones con otras instituciones gauchas como Los Reseros de Mataderos. En uno de sus recitados más reproducidos titulado "Se lo que's" Kruzich rezaba: "Se lo que's de madrugada ensillar junto al galpón / y aprovecho la ocasión pa'decir sin fantasía: / se lo que es en tierra mía ¡La Patria y la Tradición!”. ${ }^{18}$

La labor del "gaucho austríaco" como puente que, mientras difundía la labor de Leales y Pampeanos, conectaba su obra con la de otros tradicionalistas, no solo se remitió a sus presentaciones públicas en los diversos festejos. Kruzich era uno de los socios que sostenía, desde sus escritos, la revista La Carreta. Sus textos iban dirigidos hacía la promoción de actividades gauchescas en distintos puntos de la provincia. Con una mirada laudatoria, el escritor resaltaba las manifestaciones minúsculas de las ciudades que visitaba y promovía su continuidad o su reproducción. Así, por mencionar solo un ejemplo, daba a conocer para los socios de Leales y Pampeanos, el museo familiar de Arturo Digiano, un tradicionalista de Azul que había emplazado

18. KRUZICH, Rodolfo, "Se lo q'es", en Revistas de mis pagos, Buenos Aires, 2008, No 38, p. 18. 
en su hogar, y con la ayuda de toda su familia, una muestra de elementos camperos confiado en haber levantado "un templo a la tradición". ${ }^{19}$

Más allá de las actividades difundidas en su publicación bimensual desde los textos de Kruzich y de otros socios como el director, Oriente Lado Ramos, los vectores de salida de Leales y Pampeanos hacia la comunidad de Avellaneda fueron su articulación con el Teatro Experimental y la creación de la Escuela de la Tradición. Las dos instituciones favorecieron la conexión de los socios gauchos con espacios que no necesariamente se encontraban vinculados per se a la promoción de las tradiciones camperas.

El Teatro Experimental de Avellaneda (TEA) surgió como una iniciativa independiente de Julio Cesáreo Campos en julio de 1942. Con la propuesta de promover un conjunto permanente para la representación de obras escénicas en el municipio se conformó un grupo que se incrementaría en participantes durante los primeros años de funcionamiento. El director era socio de Leales y Pampeanos y junto con la colaboración de otros tradicionalistas, conformaron -desde los inicios de TEA- un comité asesor para la puesta en escena de las obras gauchescas. En el transcurso de una década, con un número variable de adherentes, el Teatro Experimental se posicionó como una referencia para la zona. Sus actuaciones se realizaban generalmente en el local del centro tradicionalista o en el Teatro Roma, pero también acudían a eventos benéficos y adaptaban sus presentaciones a escenarios diversos: fábricas, escuelas, sociedades de fomento $\mathrm{y}$ sedes de boys

19. La Carreta, órgano del Círculo Tradicional Leales y Pampeanos, Avellaneda, enero-febrero de 1952, p. 5. scouts. Las presentaciones de TEA no solo fomentaron las artes escénicas sino que a partir de las obras que representaban, de los bailes folklóricos entre números o de las alocuciones de su director se fueron conformando como un apéndice de Leales y Pampeanos en la defensa de las tradiciones camperas. ${ }^{20}$

Julio Cesáreo Campos también era un asiduo colaborador de La Carreta. En sus escritos, además de reseñar las actividades de TEA, esbozaba conceptos sobre el gaucho y lo reivindicaba como el "verdadero artífice de la patria". Con motivo de la celebración del Día de la Tradición, en 1951, Campos realizó una extensa argumentación que presentaba al gaucho como elemento fundamental en todas las contiendas bélicas de la historia nacional. La ubicuidad de la figura del gaucho quedaba plasmada en sus líneas que finalizaban vivando la reivindicación accionada a partir de los círculos criollos. ${ }^{21}$ Las presentaciones del Teatro Experimental se complementaron, desde 1948, con las manifestaciones artísticas desarrolladas por los alumnos de la Escuela de la Tradición, otra de los canales de promoción de Leales y Pampeanos.

Al momento de su fundación, la comisión directiva justificó: "La enseñanza de las tradiciones nacionales debe ser tan obligatoria como el alfabeto. Es que la misma, vendría a ser el alfabeto espiritual de la nación”. ${ }^{22}$ A partir de ese objetivo, se estableció un reglamento y se dio comienzo a lo que en un

20. La Carreta, órgano del Círculo Tradicional Leales y Pampeanos, Avellaneda, julio-agosto de 1952, pp. 5-11.

21. La Carreta, órgano del Círculo Tradicional Leales y Pampeanos, Avellaneda, septiembre, octubre, noviembre y diciembre de 1951, p. 3.

22. La Carreta, órgano del Círculo Tradicional Leales y Pampeanos, Avellaneda, enero-febrero de 1953, p. 1. 
principio conformaban las clases ofrecidas por la escuela: guitarra y danzas. Con dos lecciones semanales, aproximadamente 120 alumnos dieron inicio al primer ciclo lectivo de la institución. La Escuela de la Tradición fue incorporando cursos, alumnos y hasta una cooperadora -conformada en su totalidad por miembros del centro tradicionalistapara colaborar con las prestaciones de útiles e instrumentos. De ese modo, Leales y Pampeanos no solo se garantizaba una vía de salida hacia la comunidad de la zona sur del Gran Buenos Aires para promover su obra, sino que incorporaba un número considerable de ingresos en cuotas sociales. Los interesados en asistir a los cursos de la escuela debían completar su inscripción social en el centro tradicionalista previamente. Es decir, la actividad pedagógica que los directivos promovían no se reducía a la enseñanza de las clases sino que apuntaba a incorporar a nuevos socios en la dinámica propia del círculo criollo. Es por eso que, con solo pocos años de funcionamiento, la Escuela de la Tradición era reconocida como el "alma y nervio" de su accionar tradicionalista. ${ }^{23}$

Los cursos completaban sus prácticas con presentaciones públicas en eventos escolares, artísticos y municipales. En los años sucesivos, tanto TEA como la Escuela de la Tradición tributarían los postulados de Leales y Pampeanos y se consolidarían como nexo para establecer vínculos con otras instituciones. Los gauchos de Avellaneda, en conjunto con otras agrupaciones, como la Asociación Folklórica Martín Fierro, se consolidaron como bastiones de la tradición en la zona sur. Un determinado nivel de recepción de sus actividades se podía

23. La Carreta, órgano del Círculo Tradicional Leales y Pampeanos, Avellaneda, noviembre-diciembre de 1952, p. 1. leer a partir de las exhibiciones masivas que promovían para cada 10 de noviembre. Por ejemplo, en 1944, coorganizaron junto al Club Atlético Independiente, un programa de festejos que contemplaba conferencias, poesías, danzas y almuerzo criollo. El evento motivó la cobertura de la prensa nacional que, en general, se detenía en las celebraciones más significativas. ${ }^{24}$ Entre las relaciones que gestaba Leales y Pampeanos, su conexión con el Círculo Criollo El Rodeo, del noroeste bonaerense, estableció uno de los lazos más sólidos que configuró el entramado tradicionalista en la década del cuarenta.

\section{E1 Rodeo y los lazos de los gauchos}

\section{El Círculo Criollo El Rodeo (CCER)} fue uno de los pilares del tradicionalismo bonaerense de la época. Su emplazamiento en el municipio de San Martín, su traslado hacia El Palomar y el establecimiento definitivo en Moreno lo consolidaron como un exponente central de la zona. Su vigencia y posicionamiento en el entramado de las agrupaciones criollas se corresponden a las bases que consolidaron desde su fundación, a la intervención directa en exhibiciones públicas que se continuaron en el tiempo y a la red de vínculos que establecieron. En ese caso, los contactos que generaron los socios de El Rodeo no estuvieron circunscriptos solo a las agrupaciones que compartían el cultivo de la tradición, sino que se relacionaron con numerosas instituciones y sociedades civiles, de la zona y de regiones alejadas.

El origen de El Rodeo estuvo ligado,

24. La Prensa, Buenos Aires, 11/11/1944, p. 11. 
como en la mayoría de las agrupaciones, a la participación en actividades de a caballo. En este caso, un grupo de corredores de sortija, dirigidos por Diego Carozzo, decidió fundar en 1939 un nuevo centro tradicionalista. La fundación de la asociación era contemporánea de la institución del Día de la Tradición en la provincia de Buenos Aires, que era gobernada desde 1936 por el conservador Manuel Fresco. La gestión fresquista, que pretendía resumirse en el lema "Dios, patria y hogar", se caracterizó por el rechazo a la democracia liberal, la animadversión al comunismo y los "conceptos foráneos", y la implementación de una serie de reformas -políticas, sociales y económicascon sesgo netamente nacionalista. En ese marco, el escenario rural y sus gauchos eran reivindicados como reservorio moral de la identidad nacional amenazada y recuperados simbólicamente a partir de determinadas políticas como la fundación del museo gauchesco Ricardo Güiraldes en San Antonio de Areco. ${ }^{25}$

El contexto era propicio para la creación del CCER que tuvo su sede de reuniones en la carnicería de Carozzo -presidente por más de una década- hasta el arrendamiento de un campo de deportes. Allí se nuclearon los socios provenientes en su mayor número del matadero de San Martín. La afición por los caballos determinó la incorporación de corredores de sortija de San Isidro que posteriormente fundarían un centro tradicionalista en su radio de influencia, denominado El Lazo.

25. Sobre la gestión de Manuel Fresco, ver REITANO, Emir (compilador) El gobierno de Manuel Fresco en la Provincia de Buenos Aires (1936-1940), Instituto Cultural de la Provincia de Buenos Aires, La Plata, 2010; BÉJAR, María Dolores, El régimen fraudulento. La politica en la provincia de Buenos Aires, 1930-1943, Siglo XXI Editores Argentina, Buenos Aires, 2005.
Muchos trabajadores del ferrocarril también comenzaron a engrosar las filas de El Rodeo que contabilizaría más de doscientos asociados al cumplir una década de funcionamiento. ${ }^{26}$

Una de las prioridades de la agrupación, junto con la promoción de las prácticas ecuestres y la difusión de danzas folklóricas, fue la celebración de las fiestas patrias. En el CCER se ocuparon particularmente de fomentar el "patriotismo" de sus integrantes a través del culto a los símbolos. La elección del abanderado para los desfiles, la ornamentación preparada para las fiestas mayas y julias, así como los recitados y cantos que promovían la "argentinidad" plasmaban el leitmotiv de los tradicionalistas. En ese orden, los gauchos de E1 Rodeo fueron ganando prestigio a partir de la institucionalización de los homenajes a caballo a José de San Martín, que se realizan cada 17 de agosto, y por servir el chocolate caliente al presidente en las celebraciones del 25 de mayo. ${ }^{27}$

Tanto las fiestas criollas para celebrar las fechas destacadas por la historiografía nacional, como la institucionalización de determinados homenajes, aproximaron a los socios de la agrupación gaucha con otras instituciones y con otros grupos de aficionados por la tradición campera. Algunos de ellos

26. El número de socios se puso de relieve en una nota del presidente del CCER a la secretaría de transportes, Archivo del CCER, 28 de julio de 1948.

27. El homenaje a San Martín consistía en una cabalgata desde el correo central hasta la catedral. Allí realizaban el depósito de las ofrendas florales y adhiriendo al culto católico -que los gauchos se encargaban de difundir al interior de su agrupación- participaban de la misa y encendían la Llama Votiva. Esa luz iluminaba la peregrinación de regreso a su sede social. Ver, Círculo Criollo El Rodeo, Moreno, septiembre de 2008, año V, No 40 , pp. 32-33. 
encontraron en el círculo criollo de Santos Lugares una referencia. La comisión directiva del CCER facilitó en diferentes oportunidades no solo sus experiencias sino también las normativas fijadas en su acta constitutiva y sus estatutos. Esos documentos fueron imitados por numerosas asociaciones que se gestaron en las décadas del cuarenta y del cincuenta en la zona del noroeste bonaerense. ${ }^{28}$ Además, el reconocimiento de El Rodeo traspasó los límites provinciales. Si bien no es objeto de este artículo, es menester mencionar que su colaboración también fue requerida desde Córdobay Mendoza. ${ }^{29}$ En esa última provincia, consolidó vínculos tan efectivos que llegaron a fundar una sede con el mismo nombre en el barrio El Cano. ${ }^{30}$

La experiencia de El Rodeo en la provincia cuyana era un síntoma de una filiación más profunda relacionada a la política. Tanto los registros de la comisión directiva como los comunicados y correspondencias de diferentes socios confirmaron una expuesta

28. Por mencionar algunos ejemplos: el Martín Fierro de Jáuregui, El Fogón de Tigre, Los Rastreadores de Merlo, La Telesita de Ciudadela, E1 Lazo de San Isidro y Ricardo Güiraldes de Luján fueron asociaciones que demandaron para su organización la colaboración de los socios de El Rodeo.

29. Las relaciones en la provincia de Córdoba se gestaron a partir de Ángel Balmaceda, un amigo personal de un integrante de la comisión directiva que residía en Bulnes. Al asistir a las reuniones en sus visitas a Buenos Aires recopiló la información y la experiencia necesarias para reproducirlas en esa localidad cordobesa. Ver correspondencia entre Ángel Balmaceda y Orlando Binaghi en Archivo del CCER, agosto de 1951.

30. En el caso de Mendoza, el contacto se originó en el viaje de diez de socios a la Fiesta de la Vendimia de 1950. La intención de homenajear a San Martín los acercó al gobernador Blas Brisoli. Esa relación se cristalizó a partir de la comunión política entre los mandatarios y los gauchos de E1 Rodeo.

148 identidad peronista que se manifestó desde los primeros años de Gobierno de Juan Perón. Como hemos analizado en otros trabajos, la figura del mandatario se posicionó como elemento de culto que, en ocasiones, llegó a ubicarse en un nivel horizontal al gaucho y a la tradición rural. Esa ligazón no respondía a una motivación unilateral de los socios sino que se retroalimentaba con los discursos y las prácticas criollistas fomentadas desde el peronismo. Pese a que excede los límites de este trabajo, cabe destacar que los nexos políticos forjaron otro de los vasos comunicantes que promovieron las relaciones sociales del centro tradicionalista. ${ }^{31}$

El crecimiento y auge del CCER estuvo relacionado a ese entramado social que supo construir desde sus inicios. En el marco institucional, las redes vinculares se fueron expandiendo en la medida que la agrupación se consolidaba en la organización y en la participación de los socios. Esa plataforma le posibilitó a El Rodeo una serie de variantes para presentar sus actuaciones, desfiles y prácticas ecuestres. Al mismo tiempo, el campo donde desarrollaban sus actividades representaba un escenario adecuado para la realización de fiestas criollas o almuerzos de camaradería por lo que en numerosas ocasiones era solicitado su alquiler o préstamo por diferentes instituciones. En el transcurrir de esas interacciones se fueron solidificando vínculos con clubes sociales, organismos municipales, círculos de obreros, unidades básicas, escuelas públicas, parroquias y regimientos militares. Los gauchos de la agrupación eran recurrentemente solicitados

31. CASAS, Matías, "Los gauchos de Perón. El Círculo Criollo E1 Rodeo, tradicionalistas y peronistas (19451955)", en Prácticas de oficio. Investigación y reflexión en Ciencias Sociales, Buenos Aires, 2015, № 15. 
para diversas fiestas, inauguraciones $y$ homenajes. Las banderas argentinas y la iconografía nacionalista acompañaban sus presentaciones.

De acuerdo a lo analizado por Pilar González Bernaldo, en su estudio sobre el término sociabilidad y la pertinencia de su utilización como categoría histórica y analítica para la historia latinoamericana, se puede afirmar que ese concepto "supone la existencia de reglas y valores compartidos". ${ }^{32}$ En esa línea interpretativa se propone aquí un repaso sobre las interacciones de los gauchos del CCER, entendiendo que las numerosas solicitudes de participación que provenían de diversas instituciones presuponían determinados códigos comunes -muchas veces explícitos en los comunicados- en orden a la tradición y a la figura del gaucho.

La comisión directiva intercambió correspondencia y adhesiones, además de la señalada con los círculos criollos, con otros "cultores de la tradición" como Eduardo Trejo quien oficiaba como presidente en Argentina de la Comisión de Cultura Tradicionalista del Río de la Plata. Esa asociación había editado todos los escritos del poeta costumbrista Romildo Risso. Trejo sostuvo una relación de amistad con el escritor nacido en Uruguay hasta su muerte en 1946. De hecho, fue uno de los que impulsó un proyecto que se debatió en la legislatura del país rioplatense para incorporar su nombre a una calle de Montevideo. ${ }^{33} \mathrm{El}$

32. GONZÁLEZ BERNALDO, Pilar, "La sociabilidad y la historia política”, en PANI, Erika y SALMERÓN, Alicia (coordinadores) Conceptuar lo que se ve. François Javier Guerra, historiador. Homenaje, Instituto Mora, México, 2004, pp. 419-460.

33. Ver una reseña del debate legislativo en RISSO, Romildo, Tierra viva, Comisión de Cultura tradicionalista argentino visitó el CCER en distintas oportunidades y también ofició de anfitrión de una delegación del círculo en Villa Tucumán. En 1951, luego de una de sus visitas, Trejo envió un comunicado en el que legitimaba la autenticidad de los miembros de El Rodeo en tanto "gauchos de verdad, gauchos por fuera y gauchos por dentro”. Luego, los felicitaba explicando: "hemos observado que aquí no hay gauchos de carnaval, ni payasos vestidos de gauchos." Por último, los exhortaba a continuar en el camino de evocar las tradiciones con "respeto y seriedad". ${ }^{34}$

Otra de las personalidades que figuraban en los archivos del CCER fue Ramona Risso Patrón de Beristayn, quien a partir de sus talleres textiles y sus muestras de indumentarias tradicionalistas se había ganado el apodo de la "abuela gaucha”. Su participación había sido muy destacada en la ciudad de San Antonio de Areco en los años previos a la primera celebración del Día de la Tradición. En octubre de 1950 se le realizó un homenaje con motivo de su cumpleaños número 75 . El evento estuvo organizado en una quinta y se compuso de un almuerzo criollo, música y danzas nativas y diferentes declamaciones. En ese caso, los miembros del CCER se hicieron presentes a partir de una invitación de la institución tradicionalista La Ramada, de la ciudad de Ramos Mejía. El homenaje concluía con la entrega de un pergamino celebrando una reciente exposición de ponchos y mantas criollas. $^{35}$

Tradicionalista del Río de la Plata, Buenos AiresMontevideo, 1948, pp. 9-11.

34. Carta de Eduardo Trejo a los socios de E1 Rodeo, Archivo del CCER, 18 de noviembre de 1951.

35. Ver, nota de la institución tradicionalista La Ramada, Archivo del CCER, octubre de 1950. 
Uno de los nexos vinculantes que tuvo el centro tradicionalista fue el campo de deportes que arrendaban y que en distintas ocasiones prestaron a diferentes instituciones. En efecto, el CCER contaba, desde mediados de la década del cuarenta, con un espacio para realizar actividades ecuestres y celebraciones en la localidad de Villa Bosch, también partido de San Martín. Sin embargo, en el año 1948, se mudarían al barrio de E1 Palomar en el municipio de Morón. ${ }^{36}$ Las notas del propietario del campo reclamando la mensualidad del alquiler, como el ofrecimiento de un socio que entregaba una donación para "ponerse al día" con el pago, evidenciaban el vínculo contractual, aparentemente tácito, que se sostuvo hasta la década del setenta cuando se produciría su emplazamiento definitivo en la localidad de Moreno. El Rodeo cedió su espacio de manera gratuita a diversas asociaciones. Los trabajadores de la cuarta división del F.N.G. Urquiza, de la Capital Federal, demostraron su sorpresa y admiración por la existencia de ese lugar que describieron como: "tan típicamente criollo, donde se rememoran las costumbres de nuestras leyendas gauchas, de las glorias que fueron Santos Vega, Martín Fierro... como también lo fueron los gauchos de Güemes que dieron sus vidas para darnos ésta nueva y gloriosa nación. ${ }^{37}$ La cooperativa popular del partido de San Martín también se vio beneficiada por el préstamo del campo para realizar una fiesta criolla. ${ }^{38}$ En ocasiones, la comisión directiva

36. BINAGHI, Orlando, en video institucional del CCER, Archivo del CCER, diciembre de 1993.

37. Comunicado de José Román y Luis Fiorilli, F.N.G. Urquiza al presidente del CCER, Archivo del CCER, 24 de septiembre de 1951.

38. Comunicado de la Cooperativa popular de San Martín al CCER, Archivo del CCER, 13 de diciembre 150 no solo facilitaba el espacio sino que cedían parte de sus caballos para distintos eventos, según lo testimoniaban los comunicados de agradecimiento. Esa predisposición del CCER se manifestó también a partir de las solicitudes de otras asociaciones.

En 1942, el cuerpo de bomberos voluntarios y primeros auxilios de Ciudadela solicitaba la presencia de los socios de El Rodeo para participar en una celebración con sus equipos de carrera de sortija. Por los agradecimientos y los comunicados posteriores se dejaba constancia que los participantes del evento no solo se habían destacado en las prácticas ecuestres sino que habían desfilado y bailado el "Pericón Nacional". De acuerdo al presidente del cuerpo de Bomberos, los socios del CCER aportaron a la celebración "un marco de sano patriotismo y de plausible argentinidad". ${ }^{39}$

Una lectura similar de sus participaciones era reproducida por los mismos gauchos utilizándola como elemento argumentativo al momento de solicitar los permisos policiales para realizar festejos criollos. Por ejemplo, cuando le enviaron una nota al comisario de la primera sección de San Martín por una velada en Santos Lugares explicaban la motivación de la institución en tanto "cultivadora del resurgimiento tradicional". ${ }^{40} \mathrm{El}$ vínculo con las fuerzas de seguridad no se circunscribió a los pedidos de permisos. A partir de la coparticipación de un socio en la Cooperadora Policial de la localidad de Caseros, El Rodeo se

de 1952.

39. Nota del cuerpo de bomberos voluntarios y primeros auxilios de San Martín al presidente del CCER, Archivo del CCER, 4 de junio de 1942.

40. Nota de Diego Carozzo al comisario de la primera sección de San Martín, Archivo del CCER, 24 de agosto de 1942. 
hizo presente en distintas celebraciones. Para festejar el 25 de mayo de 1941, por ejemplo, eran convidados en pos de "transportar el ambiente moderno a aquellas épocas en que los bailes del pericón, la zamba, etc. fueran deleites de los concurrentes." ${ }^{11}$ Las interacciones con los destacamentos de policía zonales fueron consolidando esa definición que se pretendía cristalizar en la primera solicitud de permiso. En efecto, el subcomisario de la comisaría $37^{\circ}$ de la policía federal los interpelaba para participar en la preparación de los festejos de un nuevo aniversario de la Revolución de Mayo y los invitaba a reunirse en su oficina para ajustar el programa de la efeméride. ${ }^{42}$

\section{La Asociación Patriótica Guillermo} Rawson del barrio de Agronomía, en la Capital Federal, les confirmaba, a partir de una invitación, la centralidad del gaucho en las celebraciones nacionalistas. Ante la ausencia de los miembros del CCER a las fiestas mayas de 1943 por tener compromisos anteriores, en junio retomaban el convite indicando: "Nuestra fiesta (9 de julio) es eminentemente patriótica en celebración y conmemoración de la fecha histórica; por lo tanto consideramos indispensable la presencia del gaucho argentino... queremos brindar a nuestro barrio el emotivo cuadro del pasado, revivido en la actualidad por los gentiles representantes de esa institución." ${ }^{43}$ Si bien la interpretación podría perseguir un motivo concreto en orden a confirmar la presencia de El Rodeo en los

41. Nota de la Cooperadora Policial al presidente del CCER, Archivo del CCER, 17 de mayo de 1941.

42. Comunicado de Rogelio Serardo al presidente del CCER, Archivo del CCER, 29 de marzo de 1948.

43. Nota de Arturo Ferrari Bravo, presidente de la Asociación Patriótica Guillermo Rawson, al presidente del CCER, Archivo del CCER, 6 de junio de 1943. festejos, esa misma correspondencia entre gaucho y efeméride patria se asimilaba por los socios de la institución: en una carta privada a la comisión directiva, Ramón Algañaraz, miembro del círculo, explicaba su emoción por haber sido designado para "izar el pabellón nacional en la fecha más gloriosa” y agradecía a sus pares, participes en esa "cruzada de criollismo". ${ }^{44}$

Muchos de los numerosos clubes sociales y sociedades de fomento que recibieron la participación del CCER en variadas celebraciones confirmaban en sus invitaciones o agradecimientos el carácter "patriótico" de la institución y sus prácticas. El club El Porvenir de José C. Paz, entre otros, apelaba a lo que consideraba como "nuestra embajada tradicionalista" para contar con la participación de sus corredores de sortija. El Ciclón Argentino de San Martín, se sentía parte de ese "fogón gaucho" que entendía necesariamente vivo en el "corazón de todo buen argentino" y se prestaban a la organización conjunta de una fiesta criolla. El Club Caseros pretendía persuadirlos para su participación en una velada artística criolla poniendo de relieve los intereses en común de ambas instituciones en cuanto a la "difusión y mayor conocimiento de los bailes y canciones del folklore argentino". Algunos comunicados daban cuenta de la jerarquía que esas asociaciones barriales le otorgaban a la presencia de E1 Rodeo en tanto modificaban la fecha frente a su indisposición o buscaban alternativas para que enviaran al menos algún representante. El club José Hernández, de Villa Bosch, explicitaba la importancia del "patrono" compartido y, desde allí, solicitaba corredores de sortija y

44. Carta de Ramón Algañaraz a la comisión directiva del CCER, Archivo del CCER, 28 de mayo de 1952. 
elementos pertinentes para su realización. Las gratificaciones luego de los eventos concretados también exacerbaban la ligazón del círculo con la iconografía nacionalista. Luego de la celebración del 9 de julio, en 1946, el Club Resurgimiento de Capital Federal, agradecía la intervención a los "nobles gauchos de El Rodeo". ${ }^{45}$

Los reconocimientos que recibía el CCER como "institución gaucha" se relacionaban al celoso cuidado que ejercían en la reproducción del vestuario y los usos de accesorios. En efecto, la tradición difundida desde esos centros conllevaba un remarcado carácter normativo. Los tradicionalistas prestaron particular atención al uso de la indumentaria "gaucha" y su "genuina" reproducción. Esa actitud se reflejaba en un comunicado de la casa "Bijou" donde les presentaba a los miembros del círculo criollo su producción de trajes de época y confecciones de ropa para bailes nativos. El dueño del comercio, ubicado en la Capital Federal, les aclaraba en la presentación: "nuestros trabajos se ciñen estrictamente, aún en sus menores detalles, a la indumentaria tradicional." Luego les informaba que mencionando El Rodeo serían gratificados con un descuento en los precios. ${ }^{46}$ Esas vinculaciones, al mismo tiempo que expandían consensos sobre el carácter "gaucho" de los socios, facilitaban su reproducción en cuanto a los elementos externos.

El adecuado vestuario no era un detalle menor para las instituciones tradicionalistas. Los intereses de la industria cultural

45. Libro de Comunicados, Archivo del CCER, 19461952.

46. Nota de casa Bijou al presidente del CCER, Archivo del CCER, 5 de octubre de 1954.

152 norteamericana por el gaucho pampeano, visibles desde las primeras décadas del siglo $\mathrm{XX}$, habían conllevado la expansión de una representación "deformada", según los círculos criollos. Las películas protagonizadas por Rodolfo Valentino y Douglas Fairbanks, entre otras, y las producciones de Walter Disney no eran consideradas como fidedignas exponentes del "auténtico gaucho". Las aproximaciones entre los íconos de masas y los elementos del imaginario gauchesco (como el Mickey o el Goofy "gauchos") despertaron ciertos cuestionamientos en los ámbitos tradicionalistas. Sin embargo, esa aparente dicotomía era notoriamente matizada en los mecanismos de penetración que tenían los productos de esa industria en la provincia de Buenos Aires. Como bien señala Andrés Bisso, a través de los niños -y en particular de sus expresiones durante el carnaval- se evidenciaba una cierta convivencia entre las caracterizaciones relacionadas a la tradición gaucha o las vinculadas a la construcción de la nacionalidad (como los granaderos) y aquellas que se emparentaban con personajes foráneos (como Búffalo Bill o Tom Mix). ${ }^{47}$

Por otra parte, el cine norteamericano no era el único vector para la expansión de los usos comerciales del gaucho. Durante la década del treinta diversos productos apelaron a su figura como estrategia para conquistar nuevos mercados. Las publicidades de la salsa mostaza o las máquinas fotográficas Kodak

47. BISSO, Andrés, “¿El de gaucho o el de Tom Mix? Reflexiones políticas a partir de los horizontes de identidades prestadas en disfraces y personificaciones lúdicas en la provincia de Buenos Aires durante los carnavales de la época fresquista, 1936-1940”, en BISSO, Andrés, KAHAN, Emmanuel y SESSA, Leandro, Formas politicas de celebrar y conmemorar el pasado (19301943), Ceraunia, La Plata, 2014, pp. 104-135. 
eran ejemplos de esa funcionalidad. ${ }^{48}$ En general, esas promociones utilizaron al gaucho como referencia de lo autóctono y lo "nativo". De ese modo, se complementaban con la representación dominante en la industria cinematográfica nacional de la época. En términos de Matthew Karush, la Argentina rural se mostraba desde el cine como la base de una auténtica identidad nacional. En ese sentido, los films como La guerra gaucha, estrenada en 1942 y producida por la compañía Artistas Argentinos Asociados, evidenciaban puntos de contacto con los tradicionalistas en tanto reivindicaban al gaucho como encarnación del patriotismo y funcionaban como una respuesta a las influencias extranjeras promovidas desde el cine. ${ }^{49}$

El celo por la indumentaria, que era reconocido desde el comunicado de la casa "Bijou", marcó otro de los mecanismos de vinculación que tenían las asociaciones criollas. Es decir, la posibilidad de abastecerse a partir de descuentos o donaciones fue otro de los factores que contribuyó a constituir la red vincular del CCER. Algunos de los pedidos que solicitaban se correspondían al acondicionamiento del campo de deportes, pero las respuestas a sus demandas no siempre resultaban favorables. En la coyuntura de la finalización de la Segunda Guerra Mundial, la sucursal de San Martín de la Compañía de Electricidad de la Provincia de Buenos Aires se amparaba en la situación económica

48. CASAS, Matías, "Representaciones y publicaciones sobre el gaucho argentino en la década del treinta. Entre la identidad nacional, el campo literario y las estrategias comerciales", en Historia y Memoria, Tunja/Colombia, 2015, No 11, pp. 151-176.

49. KARUSH, Matthew, Cultura de clase. Radio y cine en la creación de una argentina dividida (1920-1946), Ariel, Buenos Aires, 2013, pp. 194-212. internacional y denegaba la donación de postes usados. En otras ocasiones, los pedidos eran correspondidos. La industria Corces y Cia. S. A., por ejemplo, decidió contribuir con la construcción del corral que programaba El Rodeo y aportó una donación para ese fin. ${ }^{50}$ En 1948, la Fábrica Argentina de Vidrios Planos y Anexos, emplazada en Caseros, también contribuía con una suma de dinero para mejoras en las instalaciones. ${ }^{51}$ La ligazón establecida con la industria del vidrio se continuaría en los años siguientes. Así lo demostraba un petitorio de ese sindicato para contar con la colaboración de E1 Rodeo en una celebración interna. La convocatoria se explicaba: "con ello se rememora la altiva estirpe de aquellos gauchos que con Lavalle y Güemes lucharon para legarnos una patria libre y una bandera sacrosanta." El representante sindical, José Ramón Díaz, le rogaba al presidente del CCER en nombre de los "miles de afiliados" que estarían sedientos de esas manifestaciones artísticas. $^{52}$

\section{A modo de conclusión}

En las interacciones promovidas desde $\mathrm{y}$ hacia El Rodeo se consolidó, no solo el carácter recíproco de las diversas colaboraciones, sino también el manifiesto "patriótico" de las intervenciones "gauchas". Esas reproducciones emergieron, también, en las distintas participaciones solidarias a las que los socios

50. Comunicado de la industria Corces y Cia. S. A. al CCER, Archivo del CCER, 7 de diciembre de 1950.

51. Comunicado de Fabrica Argentina de Vidrios Planos y Anexos al presidente del CCER, Archivo del CCER, 11 de agosto de 1948.

52. Carta de José Ramón Díaz al presidente del CCER, Archivo del CCER, 10 de noviembre de 1954. 
asistieron como eventos recaudadores para hospitales, cruz roja, boy scouts, etc. ${ }^{53} \mathrm{La}$ sociabilidad de los gauchos materializó intereses compartidos en orden a celebrar diversos acontecimientos, pero al mismo tiempo involucró cuestiones simbólicas. De ese modo, se reproducía una lectura del pasado nacional que colocaba a la figura del gaucho en el centro de la identidad nacional.

Esa revisión del pasado se enmarcó en un contexto de "fervor patriótico" motorizado desde distintos sectores. Las agrupaciones criollas asimilaron el nacionalismo de los años treinta y reconfiguraron las efemérides patrias en festejos gauchos que posicionaban al "hombre de la pampa" como factor promotor de la emancipación y la consolidación del Estado nacional. Los símbolos patrios, tan exaltados por los dirigentes políticos, se confundían con los elementos propios del imaginario gauchesco para concluir el cuadro de "argentinidad" que se vitoreaba en la celebración.

Las actividades públicas organizadas por la Escuela de la Tradición de Leales y Pampeanos y por el Teatro Experimental de Avellaneda proyectaban un derrotero similar en el sur de la Gran Buenos Aires. Desde sus actuaciones se promovía al gaucho como modelo de patriotismo y, a través de los recitados musicales, las obras gauchescas y las danzas se difundía una representación de la tradición nacional identificada con el espacio pampeano y sus costumbres.

53. Por mencionar algunos de los eventos, ver, invitación del Club Atlético y Social Unión Caseros, Archivo del CCER, 17 de junio de 1943; Agradecimiento de la Cruz Roja Argentina, Archivo del CCER, 8 de diciembre de 1952.
Las instituciones que compartieron las fiestas criollas o las actividades ecuestres con los socios de El Rodeo y de Leales y Pampeanos adherían, al menos discursivamente, a esa interpretación cristalizando la narrativa tradicionalista que se proponía desde esas agrupaciones. Prieto había signado la extinción definitiva del criollismo para los comienzos de la década del veinte. En su interpretación, no solo se contemplaba el desarrollo literario criollista sino también aquellas experiencias de sociabilidad que se promovieron en torno a él. Su recorte temporal le impidió visualizar la proliferación de asociaciones gauchas en los años sucesivos. Al fijar la atención en la minoritaria participación de los primeros centros criollos proyectó su decaimiento y conclusión. ${ }^{54}$ Por el contrario, las dos agrupaciones aquí analizadas contrastaron notoriamente el tiempo de languidecimiento y extinción. Los dos círculos criollos se consolidaron como testimonio de un proceso de resurgimiento gauchesco que, si bien excedió a esas asociaciones en tanto involucró determinaciones políticas particulares, tuvo en las agrupaciones civiles uno de sus pilares fundamentales.

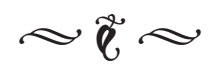

Recibido: 01 - 03 - 2016

Aceptado: 02 - 06 - 2016

Publicado: 30 - 06 - 2016

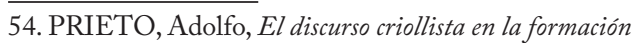
de la Argentina moderna, Editorial Sudamericana, Buenos Aires, 1988, p. 146. 


\section{Bibliografía}

AMUCHÁSTEGUI, Martha, "Los rituales patrióticos en la escuela pública”, en PUIGGRÓS, Adriana (directora) Discursos pedagógicos e imaginario social en el peronismo (1945-1955), Editorial Galerna, Buenos Aires, 1995, pp. 13-41.

BÉJAR, María Dolores, El régimen fraudulento. La política en la provincia de Buenos Aires, 1930-1943, Siglo XXI Editores Argentina, Buenos Aires, 2005.

BISSO, Andrés, “¿El de gaucho o el de Tom Mix? Reflexiones políticas a partir de los horizontes de identidades prestadas en disfraces y personificaciones lúdicas en la provincia de Buenos Aires durante los carnavales de la época fresquista, 1936-1940”, en BISSO, Andrés, KAHAN, Emmanuel y SESSA, Leandro, Formas politicas de celebrar y conmemorar el pasado (1930-1943), Ceraunia, La Plata, 2014, pp. 104-135.

CARÁMBULA DE BARREIRO, Margarita, “Elías Regules (1861-1929)”, en Revista del Sindicato Médico del Uruguay, Montevideo, 1987, pp. 7-13, disponible en <http:/www.smu.org.uy/publicaciones/libros/ ejemplares/regules.pdf> [Consulta: 10 de enero de 2016].

CASAS, Matías, "Los gauchos de Perón. E1 Círculo Criollo E1 Rodeo, tradicionalistas y peronistas (19451955)”, en Prácticas de oficio. Investigación y reflexión en Ciencias Sociales, Buenos Aires, 2015, No 15.

CASAS, Matías, "Representaciones y publicaciones sobre el gaucho argentino en la década del treinta. Entre la identidad nacional, el campo literario y las estrategias comerciales", en Historia y Memoria, Tunja/Colombia, 2015, No 11, pp. 151-176.

CONI, Emilio, El gaucho, Argentina, Brasil, Uruguay, Solar / Hachette, Buenos Aires, 1969.

DE PAOLI, Pedro, Trayectoria del gaucho, Ciordia y Rodríguez, Buenos Aires, 1949.

DEVOTO, Fernando, Nacionalismo, fascismo y tradicionalismo en la Argentina moderna, Siglo Veintiuno Editores, Buenos Aires, 2005.

GONZÁLEZ BERNALDO,Pilar, "La sociabilidad y la historia política”, en PANI, Erika y SALMERÓN, Alicia (coordinadora) Conceptuar lo que se ve. François Javier Guerra, historiador. Homenaje, Instituto Mora, México, 2004.

GUARNIERI, Carlos, Versos gauchescos y nativistas, DISA, Montevideo, 1970.

KARUSH, Matthew, Cultura de clase. Radio y cine en la creación de una argentina dividida (1920-1946), Ariel, Buenos Aires, 2013.

KRUZICH, Rodolfo, "Se lo q'es”, en Revistas de mis pagos, Buenos Aires, 13 de enero de 2008, No 38.

LEHMANN NITSCHE, Robert, Santos Vega, Imprenta de Coni Hermanos, Buenos Aires, 1917. 
LIDA, Miranda, "Por una historia política y social del catolicismo en la Argentina del siglo XX”, en PolHis, Mar del Plata, 2011, No 8, pp. 121-128.

LUGONES, Leopoldo, El payador, Otero y Co. Impresores, Buenos Aires, 1916.

MALLIMACI, Arturo, El catolicismo integral en la Argentina, 1930- 1946, Editorial Biblos, Buenos Aires, 1988.

PISARELLO, María Cecilia, Presente de Gauchos, Unión Personal Civil de la Nación, Buenos Aires, 2004, pp. 12-16.

POTASH, Robert, El Ejército y la politica en la Argentina, 1928-1945, Sudamericana, Buenos Aires, 1981.

PRIETO, Adolfo, El discurso criollista en la formación de la Argentina moderna, Editorial Sudamericana, Buenos Aires, 1988.

RAMA, Ángel, Los gauchipoliticos rioplatenses, Centro Editor de América Latina, Buenos Aires, 1994.

RATIER, Hugo et al., "Organizaciones rurales y cultura de las pampas: La construcción social de lo gauchesco y sus implicaciones”, en Etnia, Buenos Aires, 2002-2004, No 44-45, pp. 81-96.

REGULES, Elías, Versos Criollos, C. García y Cía., Montevideo, 1935.

REITANO, Emir (compilador) El gobierno de Manuel Fresco en la Provincia de Buenos Aires (1936-1940), Instituto Cultural de la Provincia de Buenos Aires, La Plata, 2010.

RISSO, Romildo, Tierra viva, Comisión de Cultura Tradicionalista del Río de la Plata, Buenos AiresMontevideo, 1948.

ZANATTA, Loris, Del estado liberal a la nación católica: iglesia y ejército en los orígenes del peronismo, 19301943, Universidad Nacional de Quilmes, Bernal, 1996. 